\title{
arte@aeropuertos.com \\ — un paseo para la imaginación
}

\section{art@airports.com}

- a break for the imagination

Nieves Alberola Crespo

Universitat Jaume I de Castelló

Resumen Desde la década de los setenta del pasado siglo, encontramos ejemplos de aeropuertos que han ido adquiriendo obra de artistas de reconocido prestigio que exhiben en sus instalaciones y forman parte de sus colecciones permanentes. Recientemente, algunos espacios aeroportuarios han optado por abrir galerías en las que se suceden exposiciones periódicamente. El objetivo del presente trabajo es investigar, examinar y dar a conocer su rica y variada inmersión artística y cultural en un paseo de solaz y entretenimiento por algunos aeropuertos de Estados Unidos y Europa.

Palabras clave Aeropuerto, arte, galería, museo, cultura, Estados Unidos, Europa.

Abstract Since the past 1970's, we can find examples of airports that have been acquiring the work of artists of well-known prestige to be exhibited at their facilities and accruing it to their permanent collections. Recently, airport authorities have staffed art galleries where exhibitions are periodically taking place. This herewith paper is aimed to research, examine and hand out their rich and variegated immersion in artistic and cultural backgrounds, an uplifting break for the imagination throughout some airports of the United States of America and Europe.

Keywords Airport, Art, Gallery, Museum, Culture, United States of America, Europe. 
Quizá pueda resultar atrevido considerar las aspiraciones artísticas de grandes y pequeños aeropuertos como un reto de competitividad. Lo cierto es que cada vez es mayor el número de espacios aeroportuarios que colaboran con museos e instituciones locales en Norteamérica y Europa. Su objetivo es poner en marcha proyectos culturales que tal vez sirvan también para combatir el estrés y las posibles demoras. Una de las iniciativas que despierta el interés de los viajeros es la posibilidad de visitar galerías o espacios expositivos permanentes que acogen obra de importantes artistas de reconocido prestigio tanto a nivel nacional como internacional. Las exposiciones de obra pictórica, fotografía, esculturas o instalaciones mejoran la calidad del servicio ofrecido al usuario del aeropuerto al fomentar el disfrute y estimular la imaginación. Para dar respuesta a nuestra creciente curiosidad sobre esta temática, iniciamos un singular viaje a diversos aeropuertos con la finalidad de descubrir su exclusiva oferta artística.

\section{Al otro lado del Atlántico - Primera etapa}

En los Estados Unidos, los grandes aeropuertos destinan de un uno a un dos por ciento de su presupuesto anual a sus programas de arte que incluyen la adquisición de nueva obra para sus colecciones permanentes, la planificación y puesta en marcha de exposiciones temporales, así como una amplia oferta de actividades culturales y educativas. El Aeropuerto Internacional de SeattleTacoma en el estado de Washington cuenta con una colección permanente que se inició con la compra de las primeras obras en 1972 y

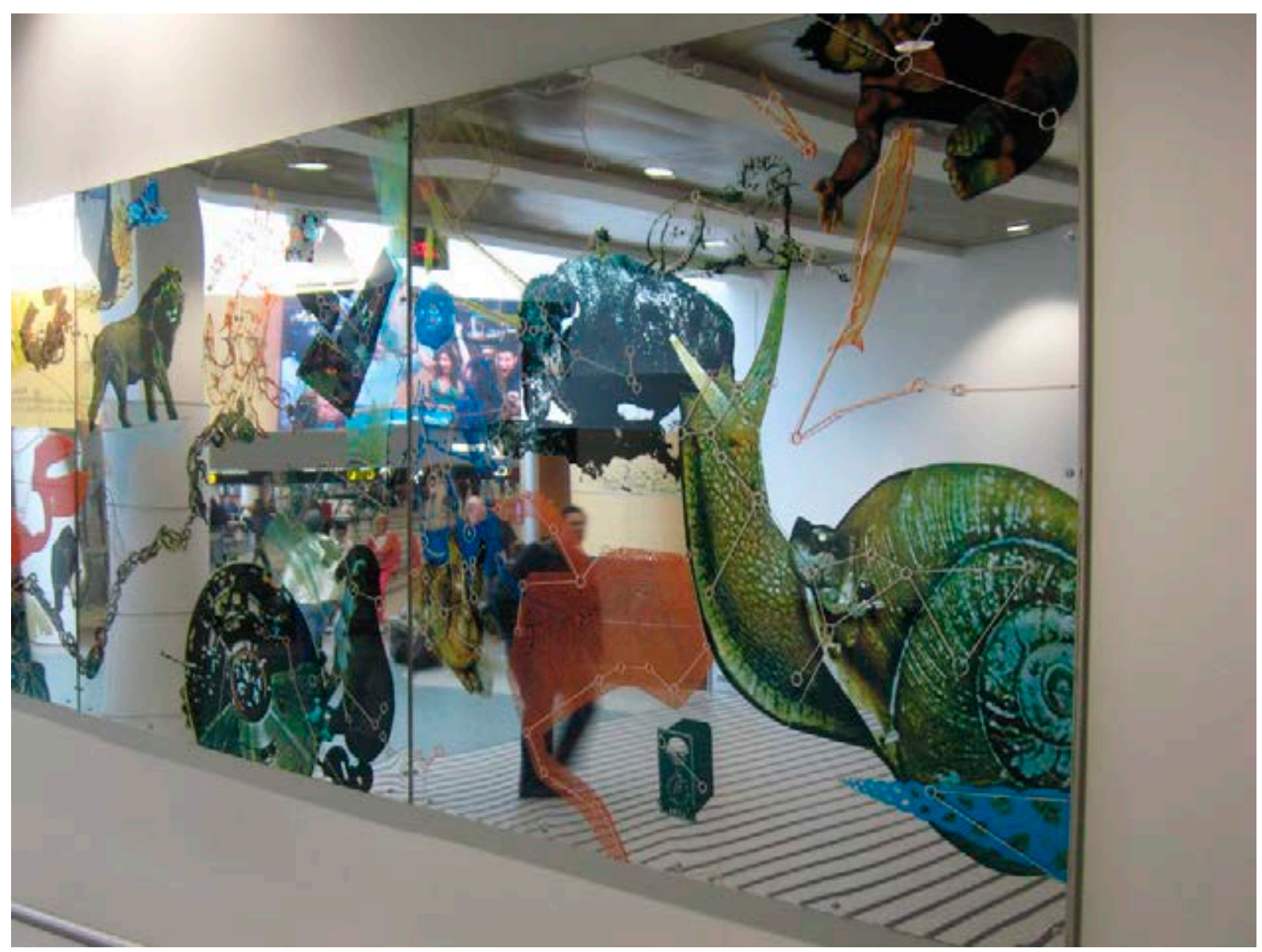

Robert Rauschenberg, Star Quaters I-IV, 1973. Fotografía: cortesía del Aeropuerto Internacional de Seattle-Tacoma, Washington 


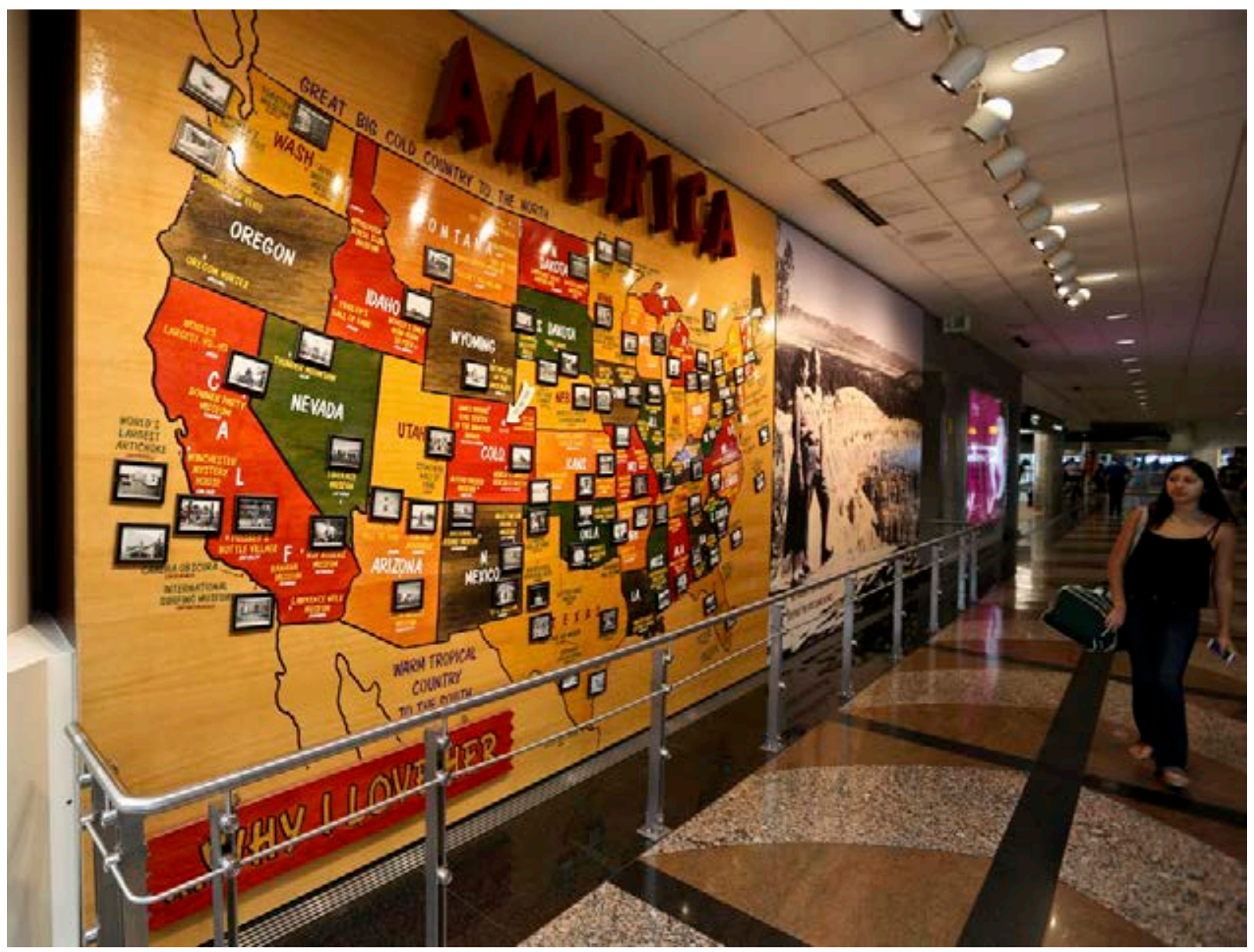

Gary Sweeney, America, Why I Love Her, 1994. Fotografía: cortesía del Aeropuerto Internacional de Denver, Colorado

atesora en la actualidad más de sesenta obras que los viajeros pueden descubrir gracias a la aplicación STQRY.

Si descargamos STQRY en nuestros móviles, podremos acceder a las breves biografías de los artistas, descripciones en detalle de sus obras, anécdotas, vídeos, etc., un paseo virtual que no nos dejará indiferentes y que nos invita, mientras esperamos que salga nuestro vuelo, a ver alguna de las 65 obras que componen la colección permanente como por ejemplo la situada en la Terminal A titulada York Factory A (1972) de Frank Stella, uno de los artistas estadounidenses más versátiles que comenzó su carrera a finales de la década de los cincuenta y que exploró las fronteras del minimalismo; en Concourse C(Alaska Airlines area), Star Quaters
I-IV de Robert Rauschenberg, adquirida en 1973 por el aeropuerto ${ }^{1}$; o acercarnos al Centro de Convenciones del aeropuerto para ver Night Flight \#1 (1973) de Louise Nevelson, pionera en la década de los 30 en dar una nueva vida a objetos que habían sido desechados. En esta pieza rescata el respaldo de una silla, molduras y discos de madera. Y si estamos cerca de las puertas de embarque C15 y C16 podremos admirar Cascadia (2019) de Cable Griffith, una impresionante instalación de veintidós paneles de vidrio pintados a mano.

Además, aquellos pasajeros que viajen con la línea aérea Delta podrán disfrutar de todas

1 En este enlace de internet, Jody Rodgers visualiza mediante un vídeo la obra de Rauschenberg: <https://www.flickr.com/ photos/breached/3310154265> [consulta: 15/09/2019] 


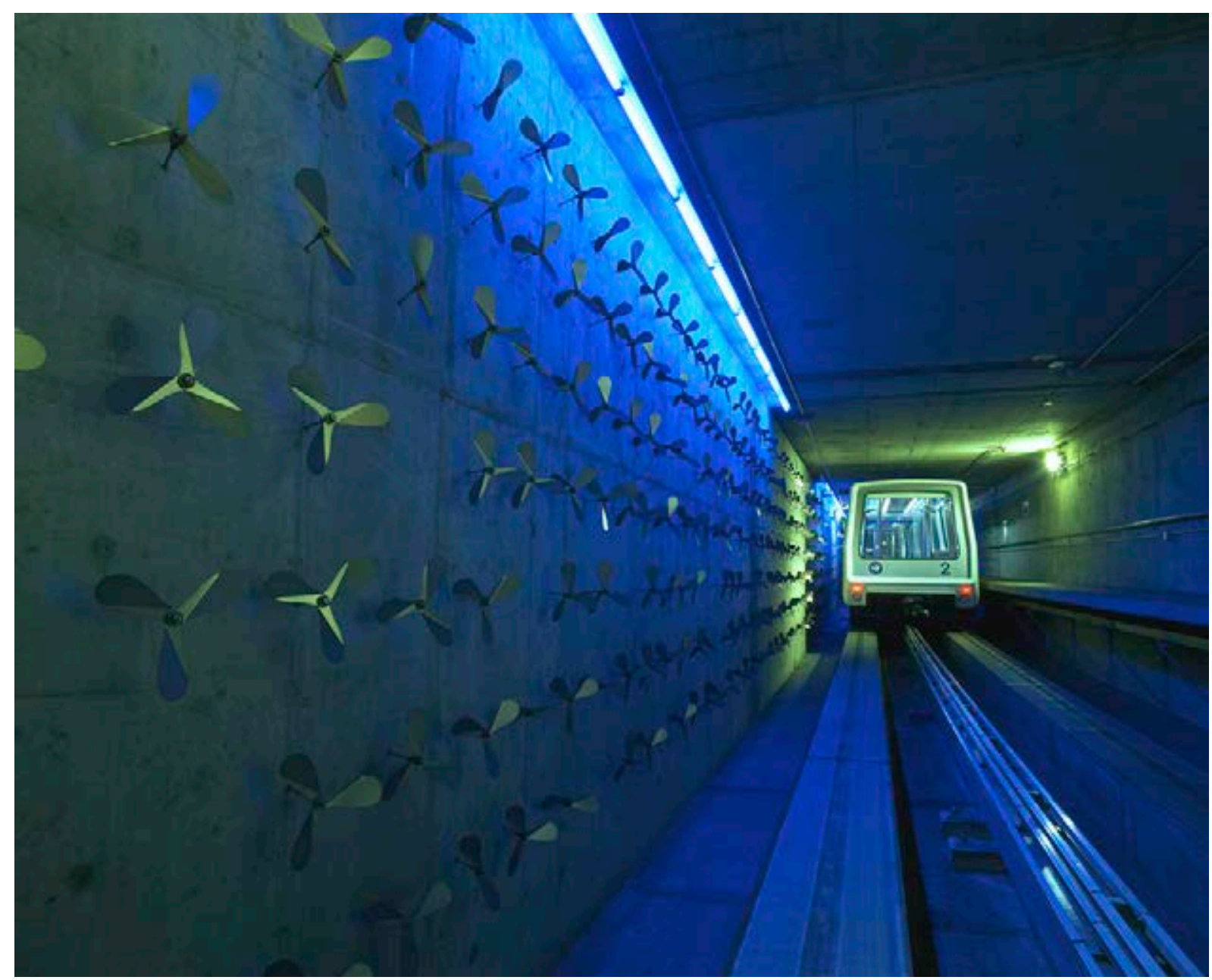

Antonette Rosato y William Maxwell, Kinetic Air Light Curtain, 1994. Fotografía: cortesía del Aeropuerto Internacional de Denver, Colorado

las amenidades que ofrecen a sus clientes en el nuevo sky club que además ofrece una zona de spa en la que se encuentra una pieza de la artista británica Rebecca J. Coles realizada con sellos de correos reciclados. En el verano de 2021 se prevé la inauguración de una nueva escultura de madera de ciprés de Nootka comisionada al artista John Grade titulada Boundary y que dará la bienvenida a los pasajeros que lleguen a la Terminal Norte.

Considerado como uno de los más activos con más de cincuenta millones de pasajeros al año, el Aeropuerto Internacional de Denver, Colorado, cuenta con una colección permanente formada, entre otras, por la obra de Gary Sweeney America, Why I Love Her (1994). Inspirada en los viajes que realizó con su familia durante su infancia y gracias a los cuales descubrió la belleza y la grandeza de sus paisajes, es un intento de rendir homenaje a las vacaciones familiares y a los lugares turísticos. Esta obra se encuentra en Jeppesen Terminal Level 5 al igual que Children of the World Dream of Peace (1995) de Leo Tanguma, un díptico en el que se exhibe por una parte la tragedia y devastación de la guerra así como su impacto en la humanidad, y por otra muestra imágenes de niños vestidos con trajes populares de todo el mundo que celebran la paz que prevalece sobre la guerra. Este mural expresa el deseo del artista de erradicar la violencia de nuestra sociedad.

Otra de las obras, Kinetic Air Light Curtain (1994) de Antonette Rosato y William Maxwell, 


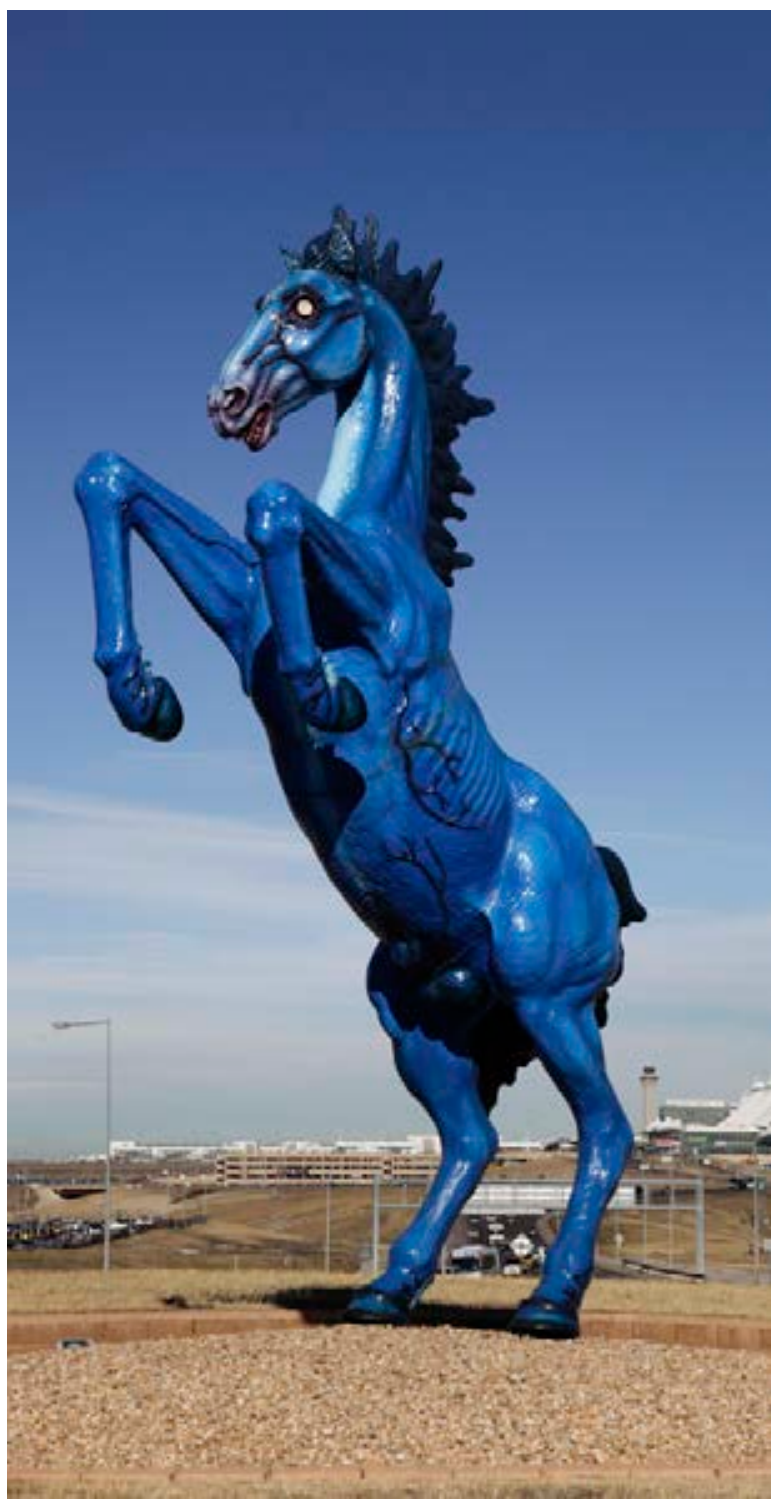

Luis Giménez, Blue Mustang, 2008. Fotografía: cortesía del Aeropuerto Internacional de Denver, Colorado

consiste en una agrupación de 5.280 hélices dispuestas en un sistema de red que cambia a medida que pasa el tren subterráneo que conecta la terminal central con las terminales satélite (Norte y Sur) que toman los viajeros para desplazarse por un túnel de una terminal a otra. Las hélices son de acero inoxidable reflectante y tienen un diámetro de doce pulgadas. El trabajo incluye iluminación fluorescente azul y las hélices se mueven gracias al viento generado por el movimiento del tren.
Cuando los pasajeros vayan a recoger su equipaje lo harán bajo la atenta mirada de dos gárgolas de bronce fundido que asoman de unas maletas, obra de Terry Allen Notre Den$v e r^{2}$. Históricamente, las gárgolas se colocaban en los edificios para su protección. Podemos intuir que la función de las del aeropuerto es vigilar y garantizar la seguridad del equipaje. Hemos de partir a un nuevo destino y será Blue Mustang, una escultura de fibra de vidrio de color azul brillante del artista de Nuevo Méjico Luis Jiménez, la pieza que veremos desde la cabina del avión y que mide 9.8 metros de altura y pesa unos 4.000 kilos. $^{3}$

El Aeropuerto Internacional de San Francisco, California, en colaboración con la concejalía de arte de la ciudad, ofrece a viajeros y residentes una colección permanente de más de ochenta obras de prestigiosos artistas locales, nacionales e internacionales. El nacimiento de su programa de arte se remonta a 1977 cuando tuvo lugar la construcción de la Terminal 3. En 1980 se creó en el aeropuerto el Museo SFO con un programa de exposiciones de una amplia variedad de temáticas que aporta una experiencia cultural y educativa a los más de cincuenta y ocho millones de pasajeros que transitan anualmente por sus instalaciones.

En la década de los ochenta más de 60 obras fueron adquiridas para las terminales T1, T2 y T3. Una de las obras que se han adquirido recientemente y que se encuentra expuesta

2 En el Aeropuerto Internacional de Sacramento, Sacramento, California, podemos ver Leap de Lawrence Argent que se encuentra cerca de la zona de recogida de equipaje. Se trata de un enorme conejo que parece haber saltado y atravesado el cristal en dirección a una maleta que se encuentra en el suelo. Hay una especie de conejos denominada riparian rabbit que se encuentra en la lista de especies en peligro de extinción y que es una especie endémica de la región de Sacramento. Se dice de él que es un animal que da buena suerte.

3 Blue Mustang también se conoce por el nombre Bluecifer. En 2006, Luis Jiménez falleció al producirse un accidente mientras creaba su obra. Gracias a la ayuda de la familia, el personal del artista así como los pintores Camillo Nuñez y Richard LaVato pudo completarse Blue Mustang que fue presentada el 11 de febrero de 2008 en el Aeropuerto Internacional de Denver. 


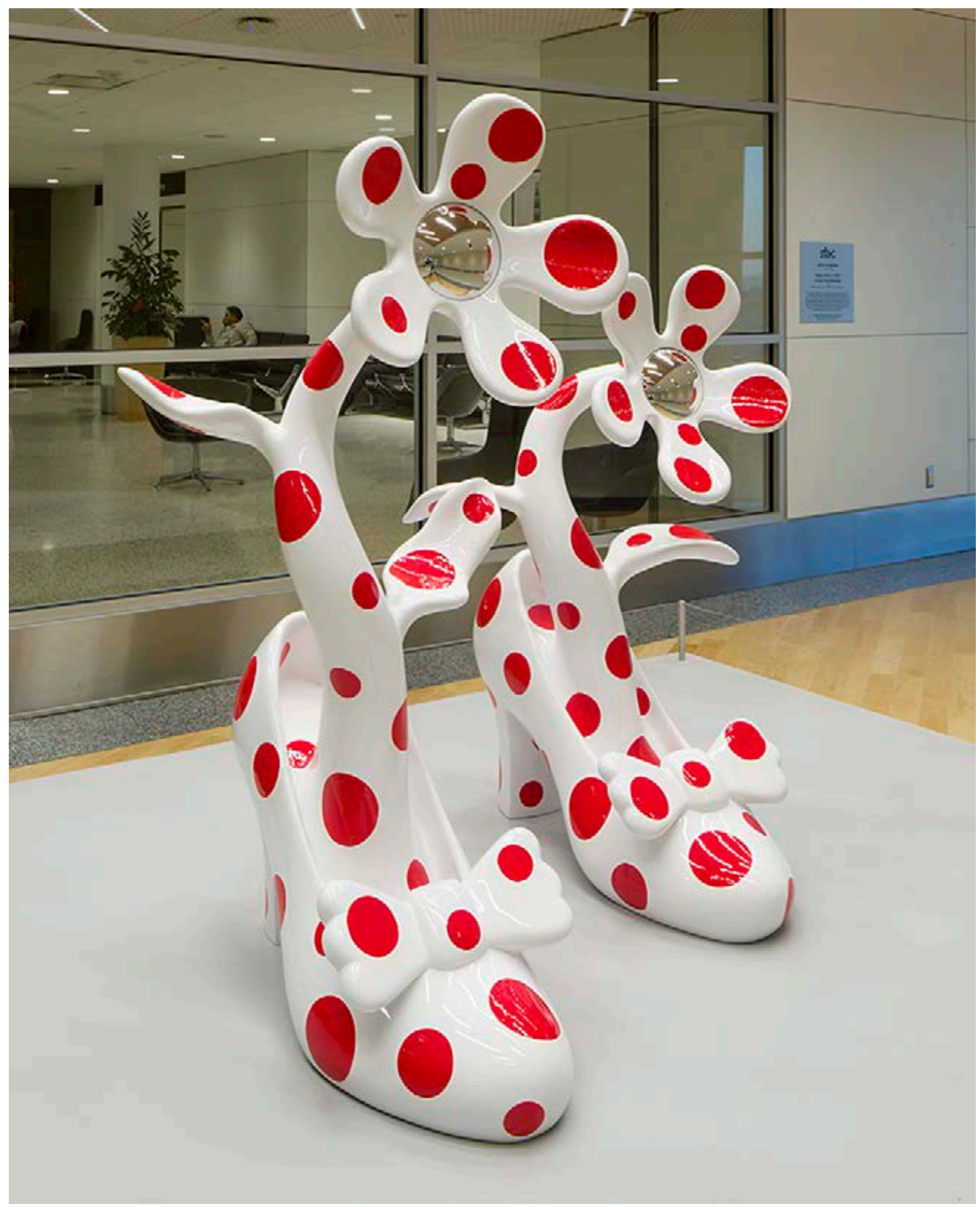

Yayoi Kusama, High Heels for Going to Heaven, 2014. Aeropuerto Internacional de San Francisco. Fotografía: Mark Matlock 
en la Terminal 1 es High Heels for Going to Heaven (2014) de la artista japonesa Yayoi Kusama. Nacida en Japón en 1929, se traslada a Nueva York en 1957 y entra en contacto con Andy Warhol y Donald Judd. Una enamorada de los lunares desde su infancia, en la década de los sesenta se la conocía como «the polka dot princess» (la princesa de los lunares) pues para ella «un lunar tiene la forma del sol, que es símbolo de la energía que mueve el mundo, que mueve nuestras vidas, y la luna es también redonda y transmite serenidad. Redondos, flexibles, llamativos, disparatados y distraídos. Los lunares se convierten en movimiento... Los lunares son el camino hacia el infinito» ${ }^{4}$. En 1993 creó una instalación para la Bienal de Venecia, Jardín de Narcisos, formada por mil quinientos globos de plástico metalizado y dos carteles «Narcissus Garden, Kusama» y «Your Narcissium For Sale». Durante la bienal y como crítica a la comercialización del arte y cómo las obras pasaban a ser tratadas como objetos de mercado, se dedicó a vender las esferas plateadas a los asistentes a cambio de un dólar vestida con un kimono dorado y plateado. A partir de esta experiencia comenzó a trabajar en esculturas e instalaciones al aire libre.

Antes de abandonar el aeropuerto, tomamos nota de dos exposiciones que tendrán lugar en 2020, Flying the Freedom Birds: Airlines and the Vietnam War (de septiembre de 2019 a junio de 2020 en la International Terminal) y Eclectic Taste: Victorian Silver Plate (de noviembre de 2019 a mayo de 2020 en la Terminal 1) y durante nuestra espera en la Terminal Internacional podemos contemplar Mondrian Meets The Beatles (2017) de Kota Ezawa. Se trata de un diorama en el que se muestra a la mítica banda británica descendiendo del avión en su primera gira por los Estados Unidos en 1964. Los rectángulos de diferentes colores superpuestos a esta escena se basan en el cuadro Composición

$4<$ https://www.mandatory.com/living/1149697-legendaryyayoi-kusama-will-blow-mind-infinity> [consulta: 20/09/2019]
C (1935) de Piet Mondrian. Ezawa combina una imagen de archivo con una composición abstracta con el objetivo de intentar liberar la fotografía de su carácter documental al tiempo que agrega una narrativa a un conjunto de campos de color primario aparentemente estáticos. Kota Ezawa imagina un encuentro entre el pintor vanguardista neerlandés y los Beatles, encuentro que en la realidad nunca tuvo lugar entre auténticos revolucionarios dentro de sus respectivos campos de creación. La historia siempre se ve tras una lente interpretativa.

Llegó la hora de embarcar. Nuestro nuevo destino: el Aeropuerto Internacional de Albany, Nueva York, en el que curadores de veinte aeropuertos estadounidenses se dieron cita en 2012 para asistir a la décima edición del taller Artes en el Aeropuerto organizado por la Asociación Americana de Ejecutivos Aeroportuarios $^{5}$. El columnista Paul Grondahl lo define como el Guggenheim de la escena artística aeroportuaria. Cuenta con un presupuesto anual de unos 150.000 dólares para financiar las exposiciones de la Galería (que permanece abierta al público de 7:00am a 11:00pm de lunes a domingo), la Concourse Gallery A, el programa de exposiciones y las visitas guiadas que son gratuitas tanto para los viajeros como para el público interesado en visitar las instalaciones.

Desde que se creó la Galería del Aeropuerto Internacional de Albany en 1998, Sharon Bates, Kathy Greenwood y el personal del Programa de Arte y Cultura han comisariado exposiciones muy diferentes $y$ atractivas a nivel temático que han proporcionado una gratificante experiencia al público de todas las edades y procedencias. Del 23 de marzo al 2 de septiembre de 2019 Everyday Perfection ha permitido a los viajeros y visitantes conectar

5 Del 15 al 17 de octubre de 2019 Phoenix Sky Harbor, Arizona fue la sede en la que se celebró la decimoséptima edición del taller Artes en el aeropuerto. 
con el pasado, concretamente con el día a día de las comunidades Shaker que llegaron a las colonias americanas en 1774 y cuyo legado se ha conservado e interpretado en gran medida gracias a los museos. Kathy Greenwood, curadora del proyecto, contactó con el Shaker $\mathrm{Mu}$ seum I Mount Lebanon y la Shaker Heritage Society, que aportaron utensilios de sus colecciones; también invitó a ocho artistas contemporáneas, entre ellas la artista Kate Hamilton ${ }^{6}$ que elaboró dos obras para esta exposición, Humble Monument (2019) y On the Verge of Merge (2019). Si bien los Shakers han disminuido en número, su influencia en el arte, diseño y arquitectura estadounidense sigue siendo profunda. Los Shakers buscaban la cercanía a la divinidad a través del trabajo llevado a cabo mediante esfuerzo y concentración.

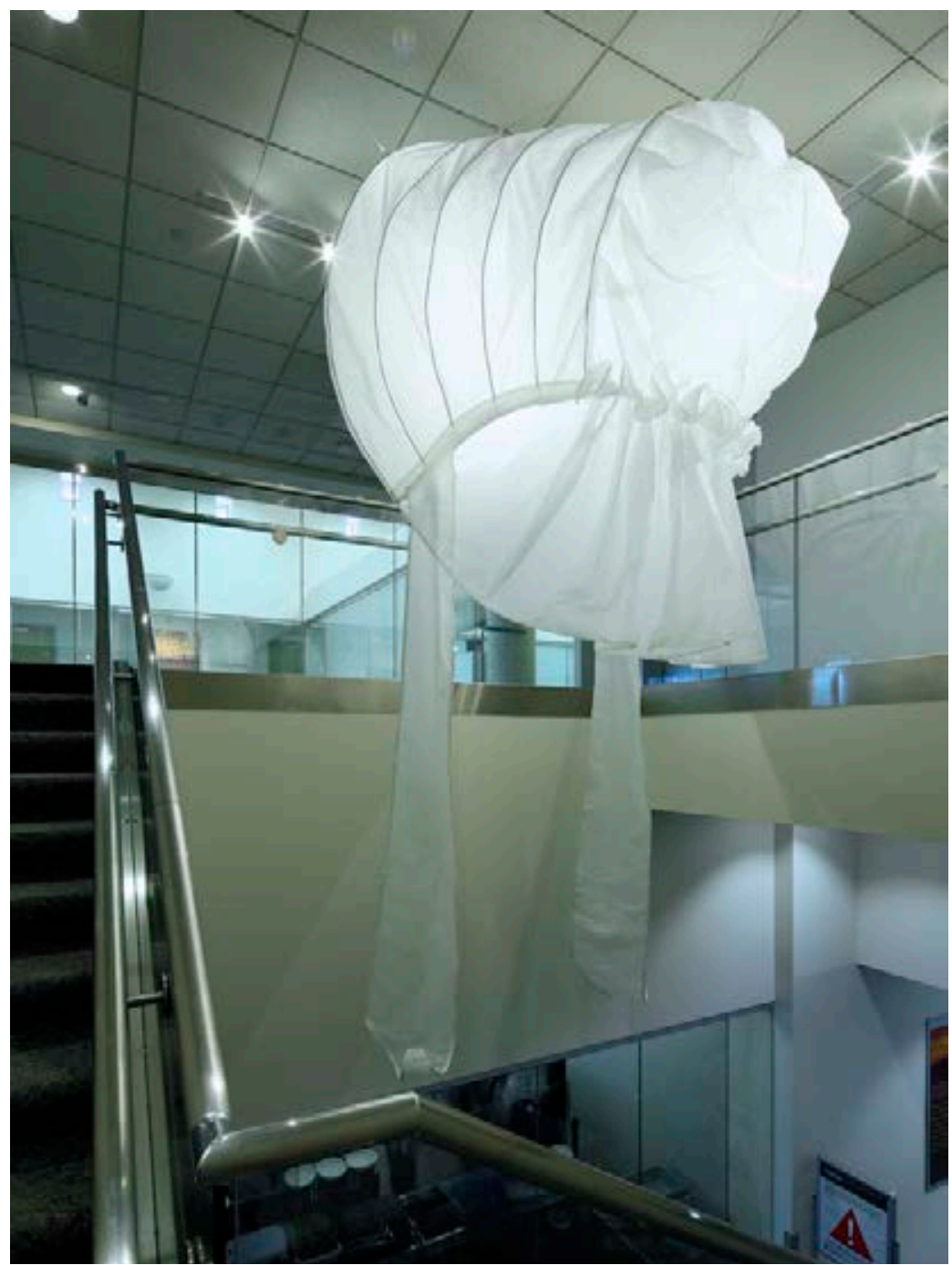

Kate Hamilton, Humble Monument, 2019. Aeropuerto Internacional de Albany, Nueva York. Fotografía: Arthur Evans
Por lo tanto, para ellos trabajar significaba devoción, entrega total, y es algo que tienen en común con artistas contemporáneas de muchas disciplinas para las que su producción artística también cumple un propósito trascendente: la producción de objetos y experiencias que reflejen y magnifiquen la percepción humana.

A pesar de no contar con una exposición permanente, el aeropuerto acoge numerosos

6 Además de Kate Hamilton, en Everyday Perfection participaron Amie Cunat (Room with Hangers, 2019), Elana Herzog (Poltergeist, 2019), Marietta Hoferer (S6, 2016), Brece Honeycutt (spooled, 2019), Laura Kaufman (Basket, 2018), Matt LaFleur (Let Us Labour, 2019) y Melissa Thorne (Untitled, 2019). proyectos e instalaciones escultóricas con contrato de préstamo de dos a tres años. Un ejemplo sería American Gothic (2012) de Benjamin Entner que estuvo en las instalaciones del aeropuerto de 2012 a 2014. Con una aguda conciencia de la historia del arte y un claro deseo de parodiar algunos de sus exponentes, Entner disfruta parodiando algunos de sus temas más sagrados mediante obras que se encuentran a caballo entre el dibujo y la escultura. Y es que sus dibujos/esculturas se inflan adaptando una imponente presencia tridimensional $y$ un movimiento que aporta carácter a sus personajes en sus peculiares situaciones. 


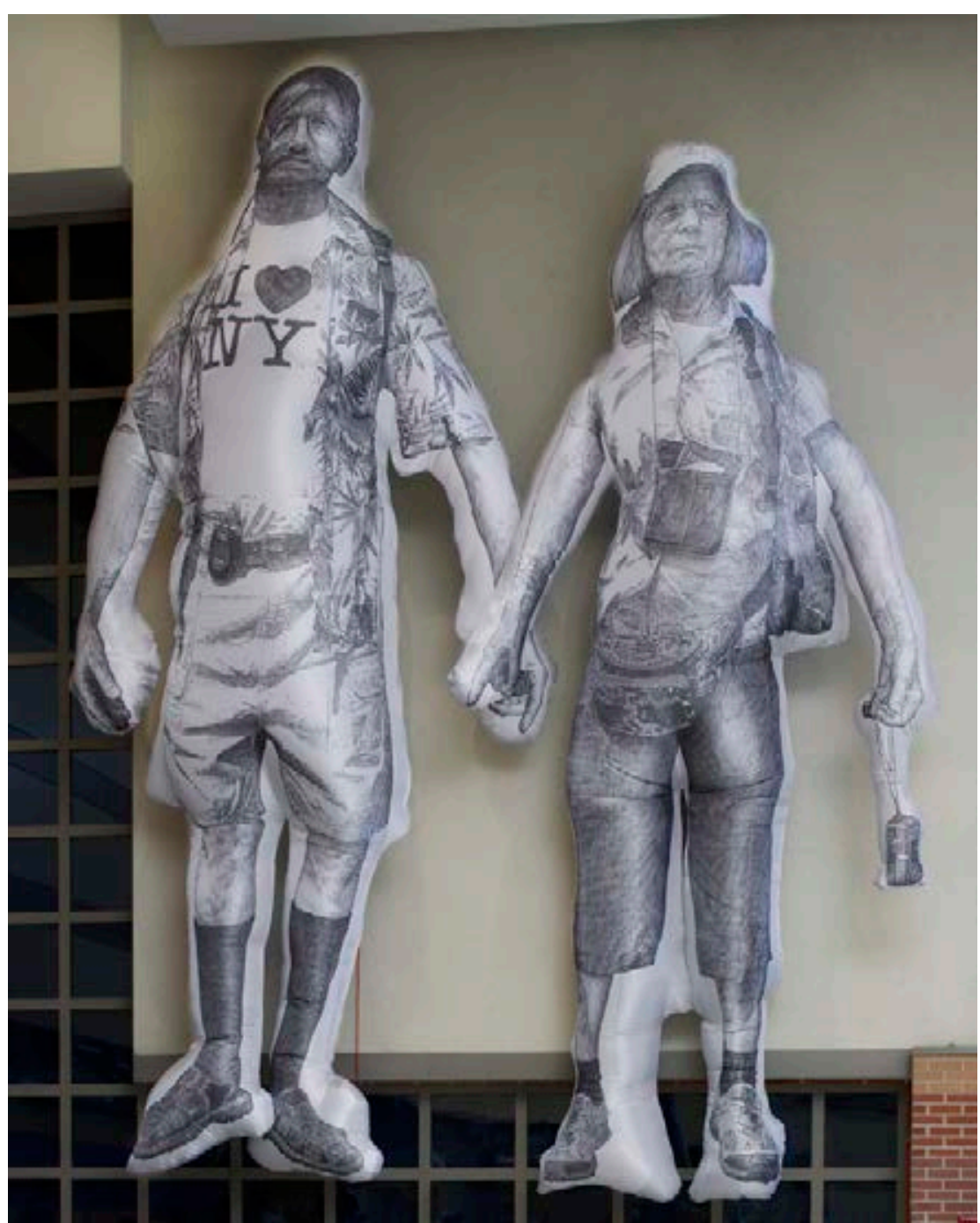

Benjamin, Entner, American Gothic, 2012. Aeropuerto Internacional de Albany, Nueva York. Fotografía: Arthur Evans

Tomando como referencia la pintura icónica de Grant Wood, American Gothic, los viajeros que nos presenta el artista neoyorquino proyectan, suspendidos en el aire, la anticipación de la diversión de la que gozarán y recordarán al final de su viaje. A título informativo, comentar que las obras expuestas en el aeropuerto de Albany se pueden adquirir y el aeropuerto se queda con un $35 \%$ de la venta -un cifra menor al $50 \%$ o $60 \%$ que se embolsan las galerías.

Por cuestiones de tiempo hemos de regresar a Europa. Viajaremos desde el Aeropuerto Internacional Hartsfield-Jackson Atlanta, Georgia, por dos sencillas razones. En primer lugar, hemos de volar con la aerolínea KLM ya que nuestro próximo destino es Amsterdam. En segundo lugar, no podemos perdernos la instalación de Steve Waldeck Flight Paths (2016) que se encuentra entre las Terminales A y B. Muchos de los pasajeros que la han visto no han podido evitar la tentación de grabar la experiencia visual/auditiva con sus teléfonos móviles y compartirla en youtube. El concepto del que parte el artista es el de crear la ilusión de estar paseando por un bosque del estado de Georgia utilizando, entre otros medios, vídeos, paisajes, proyecciones, audios y un particular uso de la iluminación. Una experiencia muy beneficiosa para los trabajadores del aeropuerto y los pasajeros $^{7}$.

\section{Bienvenidos a Europa - Segunda etapa}

En el Aeropuerto Internacional de AmsterdamSchiphol, entre las salas de embarque E y F en Holland Boulevard, se encuentra la Galería Rijksmuseum Schiphol en la que desde 2002 se puede contemplar una selección de obras originales de grandes maestros holandeses. Las

7 En el Aeropuerto Internacional de Miami podemos disfrutar de la instalación del arquitecto Christopher Janney Harmonic Convergence en la que la luz, el sonido y el color nos acompañan. https://www.designboom.com/art/miamiairport-installation-harmonic-convergence-by-christopherjanney/ [consulta: 15/09/2019] 
exposiciones son temporales y es una fantástica oportunidad para ver obras de Rembrandt, Vermeer, Jan Van Goyen, Abraham Mignon, Jan Steen, Jacob van Ruisdael o Vincent Van Gogh. Este pequeño museo nació de la colaboración entre el Museo Nacional de Amsterdam (Rijksmuseum) y el aeropuerto; es gratuito y está abierto al público veinticuatro horas al día, trescientos sesenta y cinco días al año.

Los grandes maestros flamencos, Rubens, Bruegel y van Eyck, también están en el punto de mira gracias a un amplio abanico de eventos y actividades que se inició en 2018 y finaliza en diciembre de 2020. En el corazón del Aeropuerto de Bruselas, en una sala decorada con lienzos de Rubens desde 2018 hasta abril de 2019, el equipo de artistas Skullmapping formado por Antoon Verbeeck y Filip Sterckx ha dado vida a un Cupido del lienzo flamenco La fiesta de Venus (1936) de Rubens gracias al video mapping, los hologramas y la realidad virtual. Las nuevas tecnologías les han permitido que los cuadros tomaran vida. El objetivo de estos artistas era jugar con el arte para desarrollar historias como nunca antes se había hecho, de manera original y directa, con una frescura que sorprendió a las personas que se encontraban en la sala de espera. En mayo de 2019 The Brussels Times se hacía eco de la noticia del homenaje a Bruegel el viejo por parte de las aerolíneas de Bruselas en uno de sus aviones ${ }^{8}$.

Continuamos nuestro periplo. Hemos de elegir entre los aeropuertos Paris-Charles de Gaulle o Paris-Orly. En esta ocasión nos decantamos por el primero para inspeccionar Espace Musées, un museo en el que se exponen obras de arte de diversos museos parisinos cuyo principal objetivo es visualizar el

8 Previamente las aerolíneas de Bruselas habían homenajeado a Tintin, Magritte, los Pitufos, los Red Devils e incluso al festival de música electrónica Tomorrowland, que se celebra anualmente en la ciudad de Boom (Bélgica). <https:// www.brusselstimes.com/all-news/belgium-all-news/56136/ brussels-airlines-unveils-bruegel-inspired-plane/> [consulta: 17/09/2019] patrimonio artístico francés entre los viajeros del Aeropuerto Internacional de Paris-Charles de Gaulle. Diseñado por los arquitectos del Museo d'Orsay, Espace Musées se inauguró el 15 de enero de 2013 y se encuentra ubicado en la sala de embarque de la Terminal 2E. Su primera exposición fue Rodin, las alas de la gloria en colaboración con el Museo Rodin. De abril a octubre de 2019 la procedencia de la muestra expuesta fue de la colección del Museo del muelle Branly-Jacques Chirac dedicado a las artes y culturas de África, Asia, Oceanía y las Américas.

Un año antes de la inauguración de Espace Musées, la Galería T5 abrió sus puertas en el Aeropuerto Internacional de Londres Heathrow. Ubicada en la Terminal 5, es un espacio cultural único que tiene entre sus objetivos mostrar y apoyar a artistas establecidos así como ayudar al desarrollo de las carreras de talentos emergentes. Desde su inauguración en 2012 ha trabajado en colaboración con el Hotel Sofitel en el desarrollo de exposiciones de escultura. Entre las exposiciones que han tenido lugar hasta la fecha destacar la participación del pintor Will Rochfort. Desde 2013 su obra es una constante en la Galería T5. Su mirada se centra en instantáneas de personas, desde escenas cotidianas hasta momentos íntimos en los que no faltan la energía y la intriga ya que según el joven pintor: «El cine es mi mayor inspiración. No puedo recordar la primera vez que fui a un cine, pero sí recuerdo el primer film que vi, Superman.» En sus cuadros trata principalmente con imágenes de América de las décadas de los cuarenta, los cincuenta y los sesenta. Esto es evidente en la ropa, los peinados, los objetos y telones de fondo que se combinan para proporcionar una visión única del pasado. Para el artista británico cada cuadro es diferente y se inspira en varias fuentes como el cine, los cómics, la música, el diseño gráfico, en los artistas del siglo xx, etc. Le encantan las buenas historias pues le inspiran a la hora de 


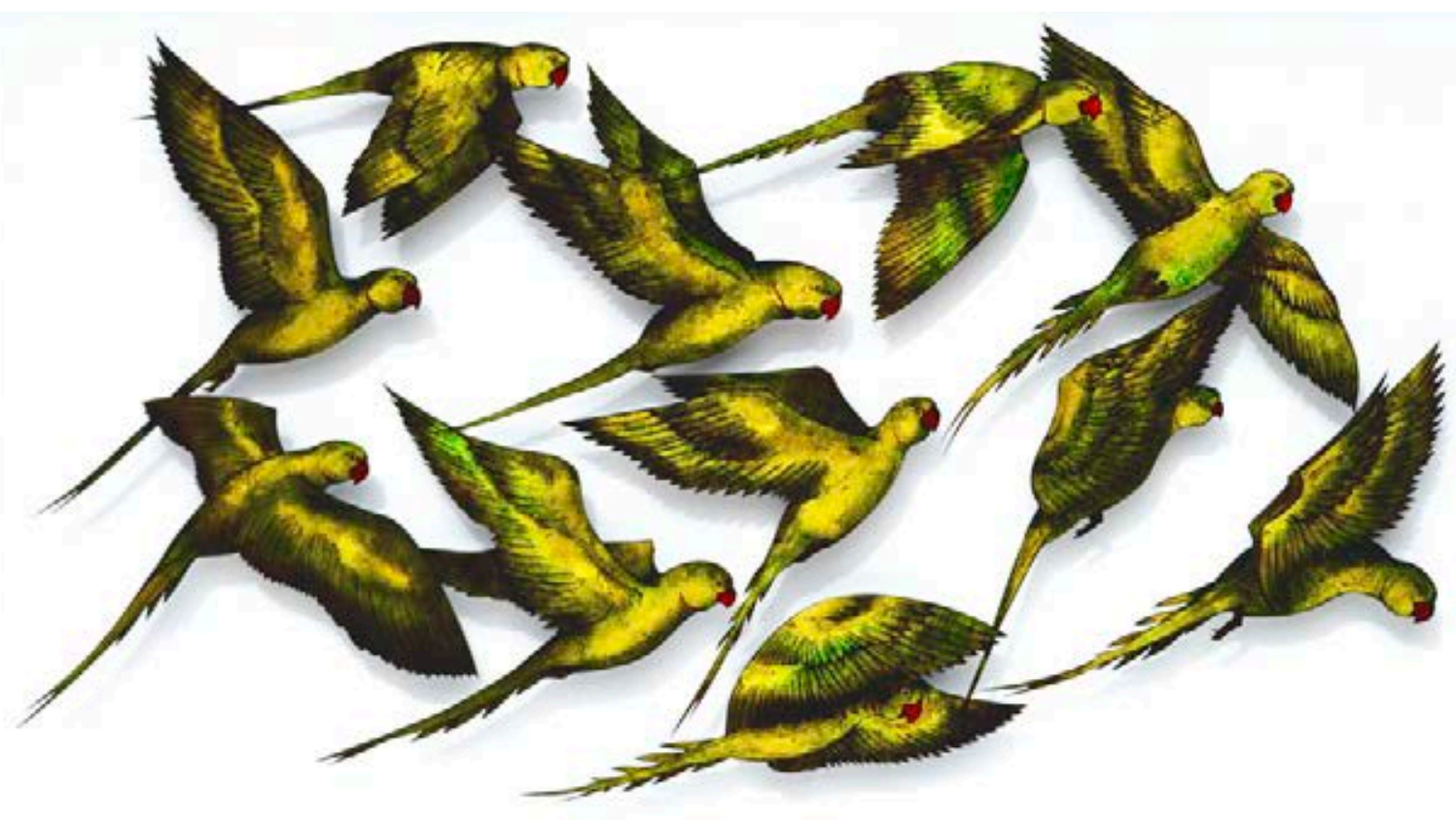

Danni Bradford, Flock of Rose ring-necked Parakeets, 2019. Fotografía: cortesía de T5 Gallery London Heathrow

pintar. Will Rochfort tiene obra en colecciones privadas en el Reino Unido, Norteamérica y África, y una de sus piezas está expuesta en el Ritz-Carlton en Bangalore, India.

Junto a Will Rochfort destaca la obra de Danni Bradford, especialista en la técnica Verre-Églomisé, término francés que se refiere al proceso de aplicar tanto un diseño como un dorado en la cara posterior del vidrio para producir un resultado de espejo. Bradford se licenció en el Instituto de Arte y Diseño de Kent en 1998. Mientras trabajaba como diseñadora para una empresa internacional, Danni Bradford descubrió su pasión por el dorado y comenzó a experimentar con las técnicas tradicionales para crear nuevas texturas. Combinando esta pasión con su amor por la naturaleza y su faceta como ilustradora, ha logrado crear un estilo propio totalmente único. Según la artista, le encanta el desafío y la complejidad de trabajar con vidrio. Cuando comenzó a aplicar el dorado, inició un extraordinario viaje que le empujó a cuestionar sus propios límites como artista.

Danni Bradford ha trabajado con Ellie Miller - una de las diseñadoras británicas más respetadas pues se trata de la única mujer que se dedica de forma profesional al diseño de tablas de surf en Europa. Juntas comenzaron el proyecto Lux Surfboards, un intento de transgredir los límites de sus respectivas formas artísticas. Esa combinación innovadora y ambiciosa entre el arte y la funcionalidad ha marcado un hito en la historia del surf y ha acaparado la atención a nivel mundial con el lanzamiento de The Aureus, la primera tabla de la serie bañada en oro de 24 quilates. The Aureus está elaborada a mano utilizando técnicas tradicionales y se inspira en las tablas de surf de aleta única de principios de los setenta que permitieron experimentar a los surfistas por primera vez la energía del océano desde lo profundo del vórtice de la ola.

Faltan unos minutos para que despegue el próximo avión que nos trasportará al Aero- 


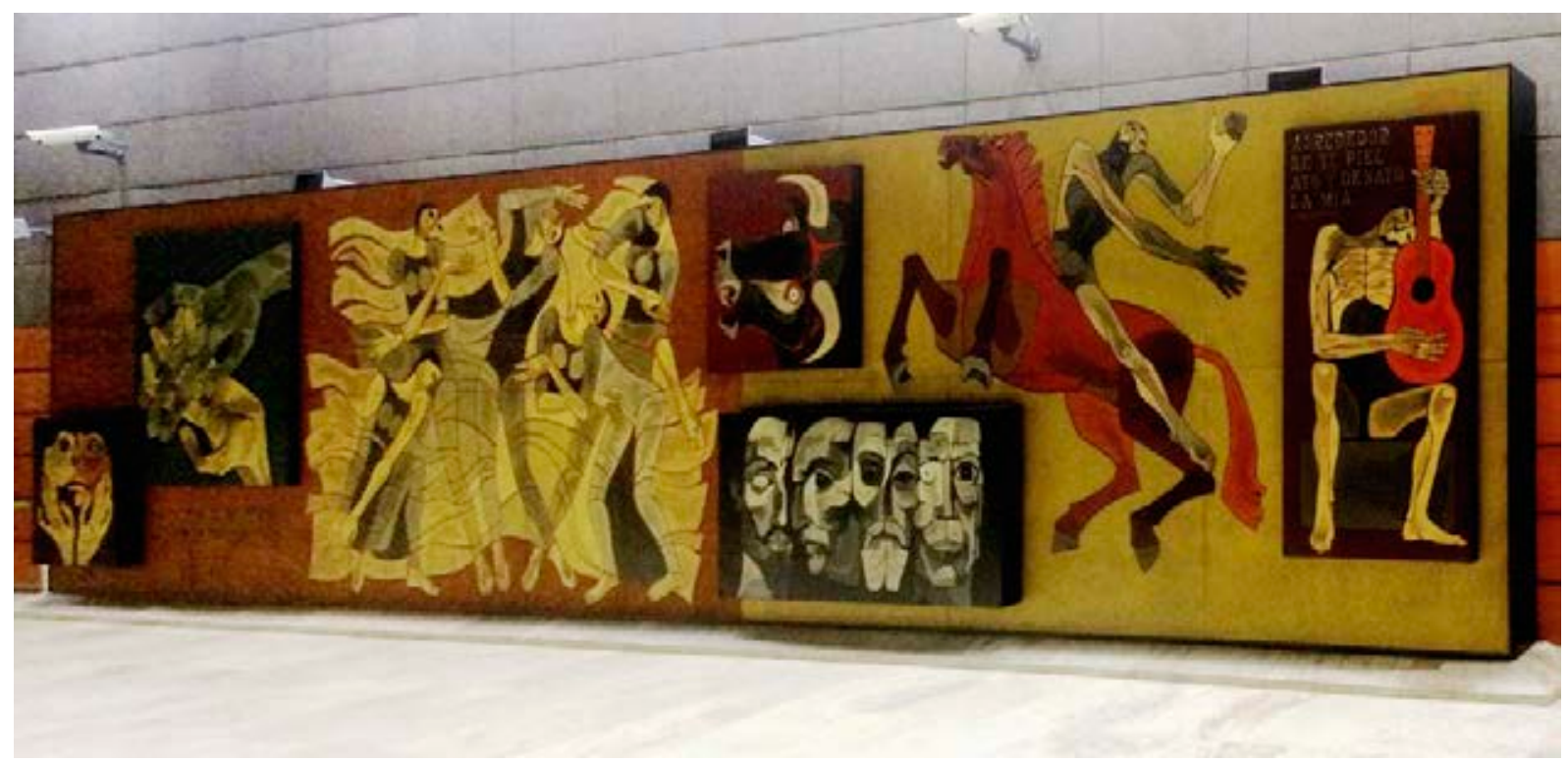

Oswaldo Guayasamín, España, 1981. Aeropuerto Adolfo Suárez Madrid-Barajas. Fotografía: Vicent F. Zuriaga Senent

puerto Adolfo Suárez Madrid-Barajas que cuenta en sus instalaciones con una notoria selección de cuadros y esculturas de la Colección Enaire de Arte Contemporáneo. La T4 del aeropuerto fue diseñada por los arquitectos Antonio Lamela y Richard Rogers; ha sido reconocida a nivel internacional como una obra de arte en sí misma y ha recibido prestigiosos premios y reconocimientos. En la zona situada entre la Terminal T4 y la T4 Satélite se encuentran dos murales de Oswaldo Guayasamín, España (1981) y América (1982). En la T2 están expuestos, entre otros, un mosaico de Javier Clavo Sin título (1981) y el de Javier de Juan El viaje (2000). En la zona de facturación de la T4 están ubicadas Las tres damas de Barajas (2004) de Manolo Valdés. Son tres cabezas de bronce de unos cuatro metros de altura, tres de ancho y otros tanto de fondo. Cada una de ellas tiene grabado un texto de Mario Vargas Llosa, expresamente escrito por el escritor peruano. También encontraremos en las distintas dependencias del aeropuerto obras de Antoni Tàpies, Joan Miró, Miquel Barceló, Josep Guinovart, Pablo Palazuelo o Eduardo Chillida.
El espacio expositivo situado en el pasillo que da acceso a la Terminal T2 desde el Metro y el Parking 2 acogió durante el mes de febrero de 2019 la muestra fotográfica Afrika-Senegal de Francesco Pinton. El fotógrafo italiano ofreció un retrato sobre Senegal, su población, vestuario, paisajes, medios de transporte, etc., así como el proceso de construcción de un nuevo conjunto de aulas en la Universidad Alioune Diop de Bambey (Senegal). La obra de Pinton invitaba a los viajeros a reflexionar sobre la crudeza de ciertas realidades que, aunque parecen muy lejanas, están más cerca de lo que creemos. Y durante el mes de junio de 2019 el espacio acogió la exposición Mujeres de cerca de la pintora de origen mejicano Maribel Moratilla en la que presenta retratos de mujeres -unas famosas, otras anónimas- con un denominador común: todas ellas son mujeres que, como dice la artista, de alguna u otra forma han hecho soñar y disfrutar. En la muestra encontramos rostros conocidos de mujeres científicas, pintoras, actrices, creadoras como Frida Kahlo, Florence Nightingale o Amy Winehouse, así como de mujeres que representan otras culturas, mujeres amantes del arte, de los viajes. 


\section{Castellón-Costa Azahar - Último enlace}

Aquellos pasajeros que opten por viajar desde el Aeropuerto de Castellón-Costa Azahar tendrán la oportunidad de visitar la Galería «Sala 30» situada en el primer piso de la terminal, al lado de la zona de embarque. La dirección artística de la Sala 30 la asume el Museo de Arte Contemporáneo Vicente Aguilera Cerni de Vilafamés (MACVAC), ${ }^{9}$ un referente cultural con gran proyección exterior que dispone de 29 salas por lo que la Galería del aeropuerto se concibe como una extensión que da la bienvenida no solo a obra de artistas consagrados sino también de artistas emergentes. En esta iniciativa colaboran el Aeropuerto de Castellón, el MACVAC y la Agencia Valenciana de Turismo.

Desde su inauguración el treinta de julio de 2017, la Sala 30 ha albergado cuatro fascinantes proyectos. Cal.ligrafies convergents, exposición comisariada por Patricia Mir, reunió doce obras de artistas emblemáticos de la extraordinaria colección que atesora el MACVAC: Aurora Valero, María José Ricós, Oswaldo Guayasamín, Antoni Tàpies, Néstor Basterretxea, Ramón de Soto, Ricardo Carpani, Beatriz Guttmann, Artur Heras, Carmen Grau, Cantalapiedra-Bellido y Pilar Carpio. Según Patricia Mir, el proyecto nació del deseo de establecer un diálogo de a dos entre obras que pese a pertenecer a corrientes diferentes (la figuración y la abstracción) pudiesen tener nexos en común.

En este peculiar recorrido metafórico y artístico conversaron, por ejemplo, el ecuatoriano Oswaldo Guayasamín y Antoni Tàpies. Las manos de la angustia frente a Tres cartones. Dos potentes propuestas cuyo grito de denuncia resulta atemporal. Unas manos

9 El 11 de octubre de 2019 se celebró la Xvi Gala de los Premios Radio Castellón en el Auditori i Palau de Congressos de Castellón. El Premio Arte Radio Castellón fue otorgado al MACVAC, galardón que fue recogido por la directora del $\mathrm{Mu}-$ seo, Rosalía Torrent.

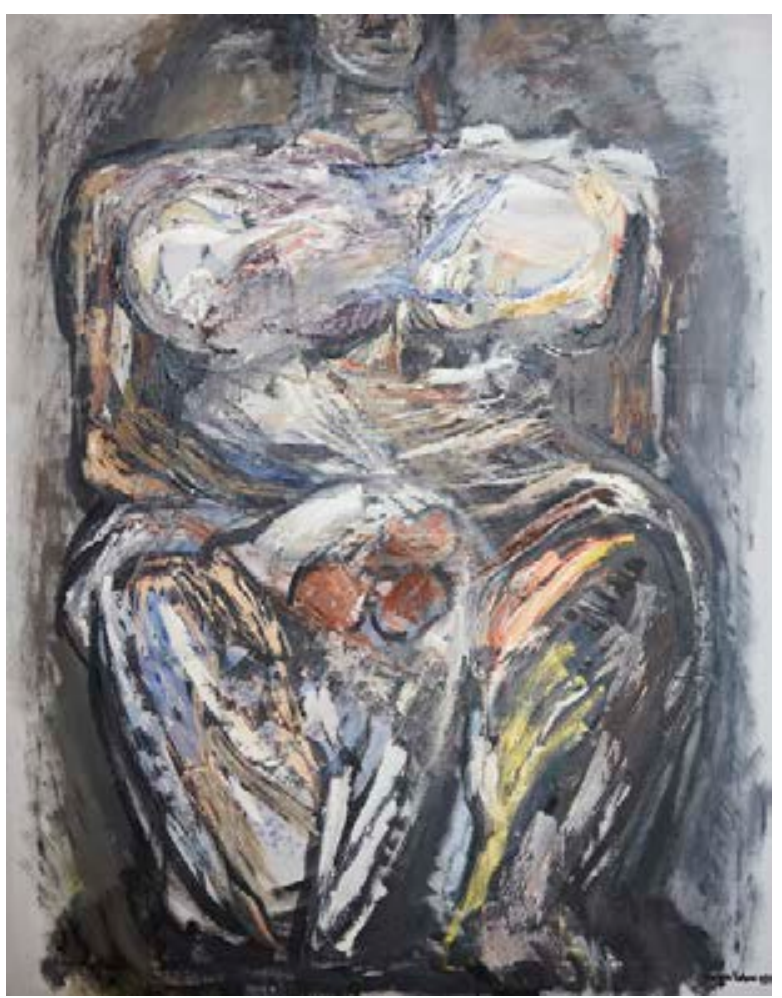

Aurora Valero, Mujeres mito, 1990. Fotografía: MACVAC

poderosas, que aprisionan un rostro cadavérico, expresan la sinrazón de la crueldad y la violencia; frente a ellas, un collage de materiales de una pobreza sobrecogedora -apenas un listón de madera, un trozo de tela y tres cartones recortados de forma irregular- enmascaran un profundo análisis de la condición humana. Otro diálogo que captó la atención y despertó todo tipo de emociones en los espectadores fue el que se estableció entre el toro desafiante de Artur Heras (Sangre, oro, mierda, 2005) y el paisaje de la artista valenciana Carmen Grau $(S / T, 1979)$-figuración y abstracción frente a frente, creaciones que exhiben humor e ironía en un juego continuo con los materiales.

Bajo el sugerente título Nunca los lejos estuvieron tan cerca se presentó de forma individualizada una muestra de la producción del artista Joël Mestre el 17 de febrero de 2018. Las ocho pinturas seleccionadas fueron realizadas entre 1997 y 2017 en torno a un tema que inquietaba al artista: la conciliación 
y la convivencia de la pintura con el entorno virtual y tecnológico. Joan Feliu, comisario de la exposición, decía el día de la inauguración que el texto que había escrito para el catálogo respondía al propio viaje que Joël y él habían realizado sobre todo a través del correo electrónico y las llamadas telefónicas, pues únicamente pudieron charlar cara a cara en un par de ocasiones. En sus conversaciones analizaron las formas de relación que las personas tenemos hoy en día con el uso de la tecnología, que no son ni mejores ni peores pues en todo medio y momento establecemos filtros para evitar compartir nuestro yo privado. Para Mestre, el exceso de imágenes y su consumo han hecho de la pintura «un peculiar antídoto. Gracias al acto de pintar, podemos volcar nuestras inquietudes, demostrar nuestras habilidades, revelar también nuestras carencias, nuestras prioridades pero también nuestro desinterés». Una de las obras que más llamó la atención fue De Sodinka a la Paloma $(2007)^{10}$ en la que unos trazos negros cubren un avión que es reconocible por su sombra proyectada -preciosa metáfora del salto ficcional al que nos acostumbra el cine o el teatro y que deberíamos asumir en nuestras vidas y especialmente en el arte.

Coincidiendo con la exposición de Joël Mestre, se dio un paso más en la habilitación de espacios expositivos del aeropuerto con la inauguración de la escultura Totem (2017) de Blas y Pablo Montoya (Trashformaciones) en el exterior de la terminal, junto al acceso principal. Totem es una escultura de gran formato elaborada íntegramente con desechos metálicos procedentes de la sociedad de consumo a los que los artistas desean dar una segunda vida. Pablo Montoya comentó que tras realizar una cuidadosa selección de todo aquello que entraba en la chatarrería familiar, en esta ocasión optaron por reciclar chapas de acero

10 Sodinka es el pueblo en cuyo término está el aeropuerto de Bilbao, que se llama La Paloma por la forma de su edificio. inoxidable procedentes de talleres. En cuanto a la base de la escultura, los artistas se decantaron por crear un suelo de acero pulido para generar la ilusión de que la escultura estaba flotando en el aire, en relación con la actividad del aeropuerto.

Inquietante figura humana, el tercer proyecto expositivo, se abrió al público el 19 de octubre de $2018^{11}$. En esta ocasión se contó con la participación del Museu de Ceràmica de l'Alcora que aportó obra de Eglé Einikyté-Narkeviciene, Paola Grizi y Paolo Porelli. De la colección del MACVAC viajaron en esta ocasión piezas de Manuel Millares, Ernesto Bailo y Nuria Torres. De colecciones privadas las piezas de Sergio Luna, Paco Puig y Ekaterina Kornilova. También el artista Miguel Ángel Gil contribuyó con una pieza de su propia colección. De la muestra comentar, a título ilustrativo, la obra de Sergio Luna Agujero negro de su serie Composites (2009-2012). El artista murciano parte de imágenes compuestas a partir de sesiones fotográficas sobre una misma persona, introduciendo la cuestión del tiempo en este tipo de retratos como si se tratara de secuencias condensadas en un mismo fotograma y aplicando esas prácticas fotográficas a la pintura ${ }^{12}$. En segundo lugar, Make Up (2017) de Nuria Torres, en la que pequeños personajes pintan los labios de un globo de porcelana. A Torres le gusta trabajar con el simbolismo con la finalidad de que surjan distintas lecturas que nos pueden hacer

11 Las obras que formaron parte de la exposición fueron S/T (1961) de Manuel Millares, Juntos y separados (1979) de Ernesto Bailo Xerri, Mujeres Sentadas (1981) de Paco Puig, Colombina (1997) de Ekaterina Kornilova, Vital Breath (2015) de Paola Grizi, Votive Wall (2017) de Paolo Porelli, Poisonous Pride (2017) de Eglé Einikyté-Narkeviciene, Deceso de la muerte (2017) de Miguel Ángel Gil y Make up (2017) de Nuria Torres, esta última fue cedida al MACVAC por la colección Marte.

12 Según los comisarios de la exposición, Rosalía Torrent y Joan Feliu, «nos interesaba la interacción con el espectador ya que según el punto de visión, el rostro que predominaba era el posado sobre una gasa exterior o el que expresaba sentimientos de una imagen retrenqueada en el interior de una caja». 


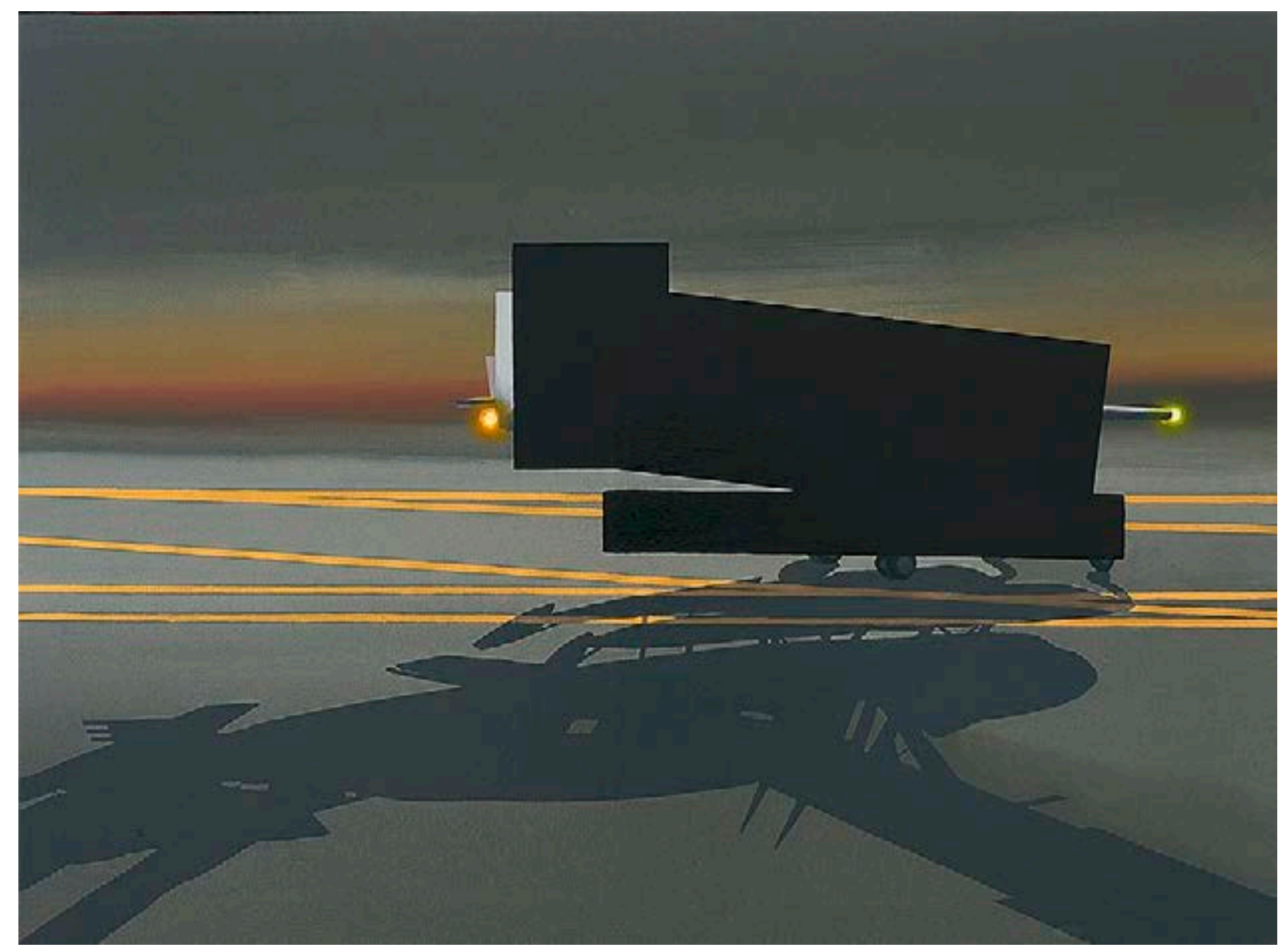

Joël Mestre, De Sodinka a La Paloma, 2007. Fotografía: cortesía del artista

pensar, reflexionar o simplemente reír. En este caso, título y obra nos invitan a meditar sobre el cuidado de nuestra imagen. Y finalmente, la composición de Paolo Porelli Votive Wall (2017). Sus figuras de cerámica, surrealistas y pop a partes iguales, son como comentarios irónicos sobre los excesos y obsesiones de la sociedad global y la enorme influencia que lo material tiene en el individuo. Imágenes contemporáneas que brindan acceso a una dimensión arquetípica de la realidad.

La cuarta aventura expositiva, que se inauguró en junio de 2019 en la Sala 30, se tituló CV-13 En ruta, aludiendo a una de las vías de comunicación de acceso al aeropuerto. Este proyecto expositivo abordó la temática del viaje en el más amplio sentido del término (viaje de la mirada, de la memoria, de las sensaciones, etc.) tanto desde la perspectiva del artista como del viajero. Según los comisarios de la exposición ${ }^{13}$, la experiencia viajera ha evolucionado gracias a las nuevas tecnologías y como consecuencia se ha despojado al viaje de su naturaleza iniciática y exploratoria. No queda rincón de la tierra del que no tengamos imágenes o noticias, del que no hayamos visto un documental o explorado a través de la literatura. Esas noticias convierten el viaje en deseo, pero también, en ocasiones, en frustración. Los viajeros se pueden encontrar con fronteras que muchas veces son infranqueables sobre todo para los más débiles, que, en lugar de puertas automáticas y carteles de bienvenida, se encuentran con

13 CV-13 En ruta fue comisariada por Nieves Alberola Crespo y Vicent F. Zuriaga Senent. 


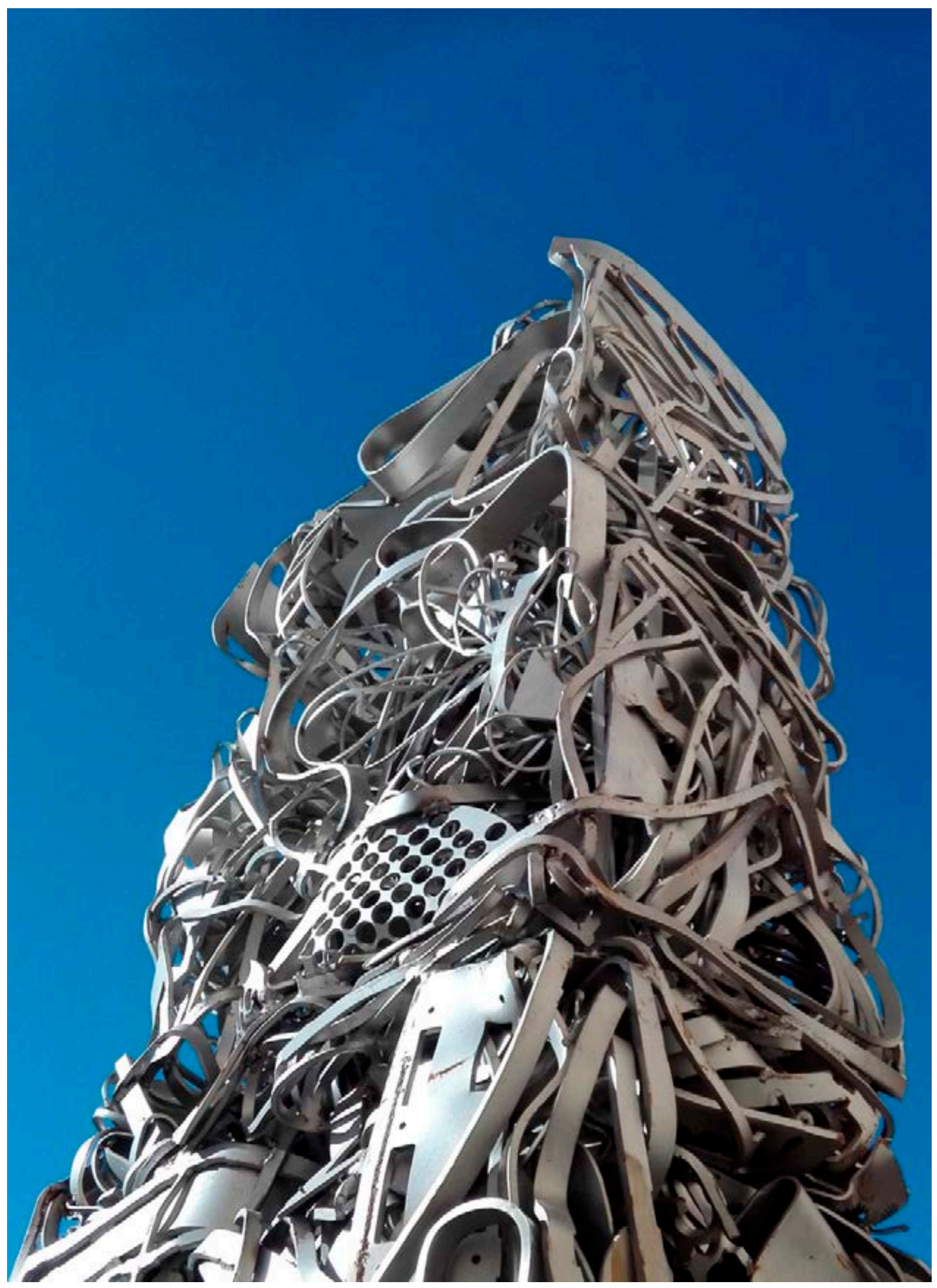

Blas y Pablo Montoya, Totem, 2017. Aeropuerto de Castellón. Fotografía: MACVAC 


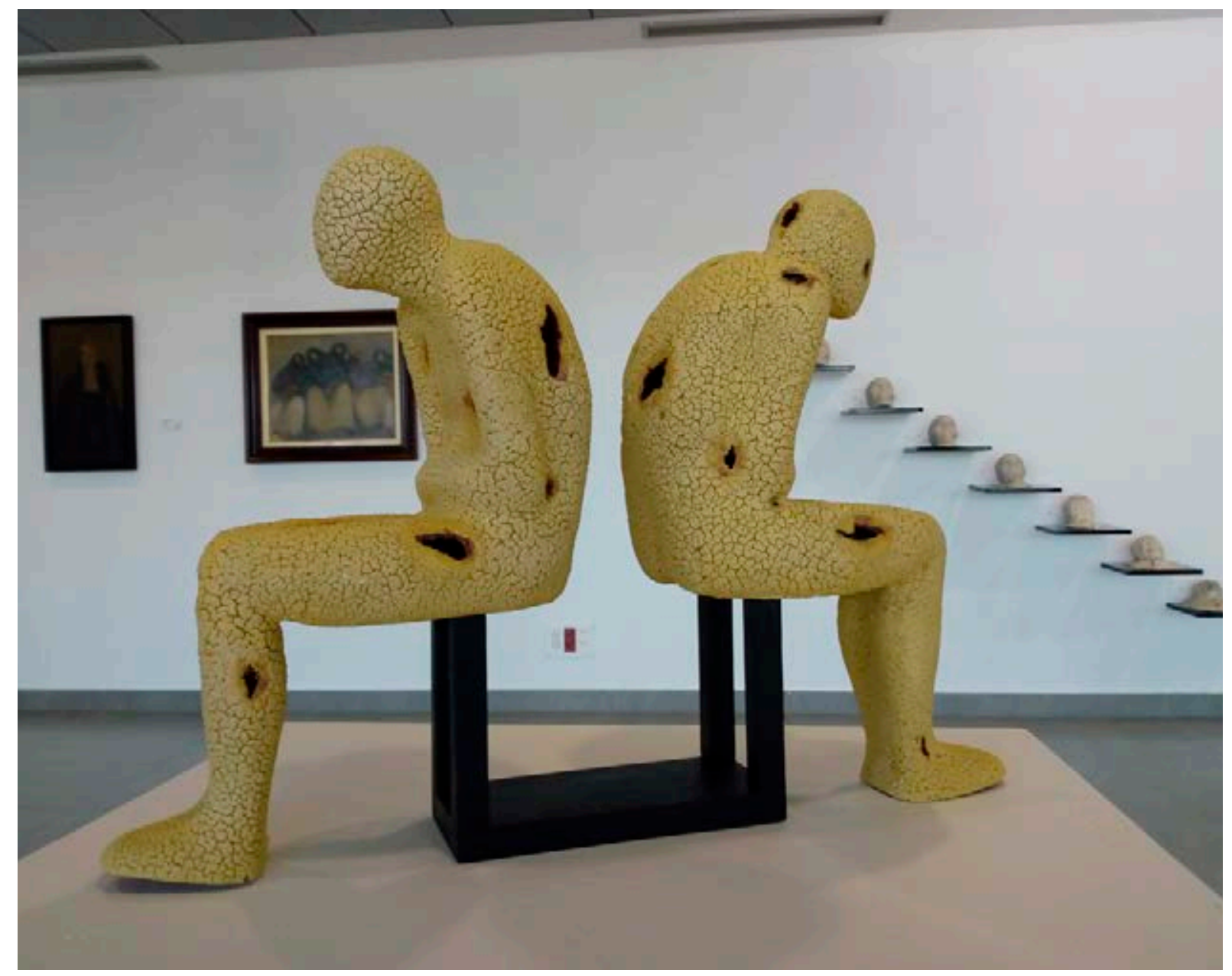

Sala 30. Exposición Inquietante figura humana, 2018. Aeropuerto de Castellón. Fotografía: MACVAC

muros, concertinas y centros de extranjería (Alberola Crespo \& Zuriaga Senent, 2019: 19).

La muestra se presentó como un viaje que se iniciaba en la Sala 19 del MACVAC donde se encuentra Cabras (1949) de Rafael Zabaleta, cuadro en el que un pastor con su rebaño nos da la bienvenida y nos habla del viaje ancestral y trashumante al tiempo que nos transporta al paisaje interior de la antigua Vía Augusta que transcurría cercana a la CV-13 y así nos emplaza a dirigir nuestros pasos a la Sala $30 \mathrm{del}$ MACVAC que se encuentra en el Aeropuerto de Castellón.

En esta ocasión, se exhibieron seis obras de los fondos del Museo en la Sala 30: Tarde de circo
(1930) de Celso Lagar, Campesinos saludando al tren (1954) de Ricardo Bastid, Aunque es tu habitación pues es de donde partes (1985) de Lorenzo Miralles y la escultura Porta Falsa (1992) de Francesc Torres Monsó. En el hall dela terminal, el lienzo Pintar la mar (1984) de Manuel Boix. Por otra parte, los comisarios se pusieron en contacto con artistas que residen y desarrollan su activad artística en la Comunidad Valenciana. Así pues, también se contó con lienzos de Carmen Sanz (Viajes, 2019), Amparo Domínguez (UNITED, 2015), Santi Tena (Preparados para el impacto, 2018), Jesús Llopis (American Bikes, 2017), y el grupo MARTILlopis (Camí Santiago, 2016), así como con las instalaciones de Victoria Cano (Libros vo- 


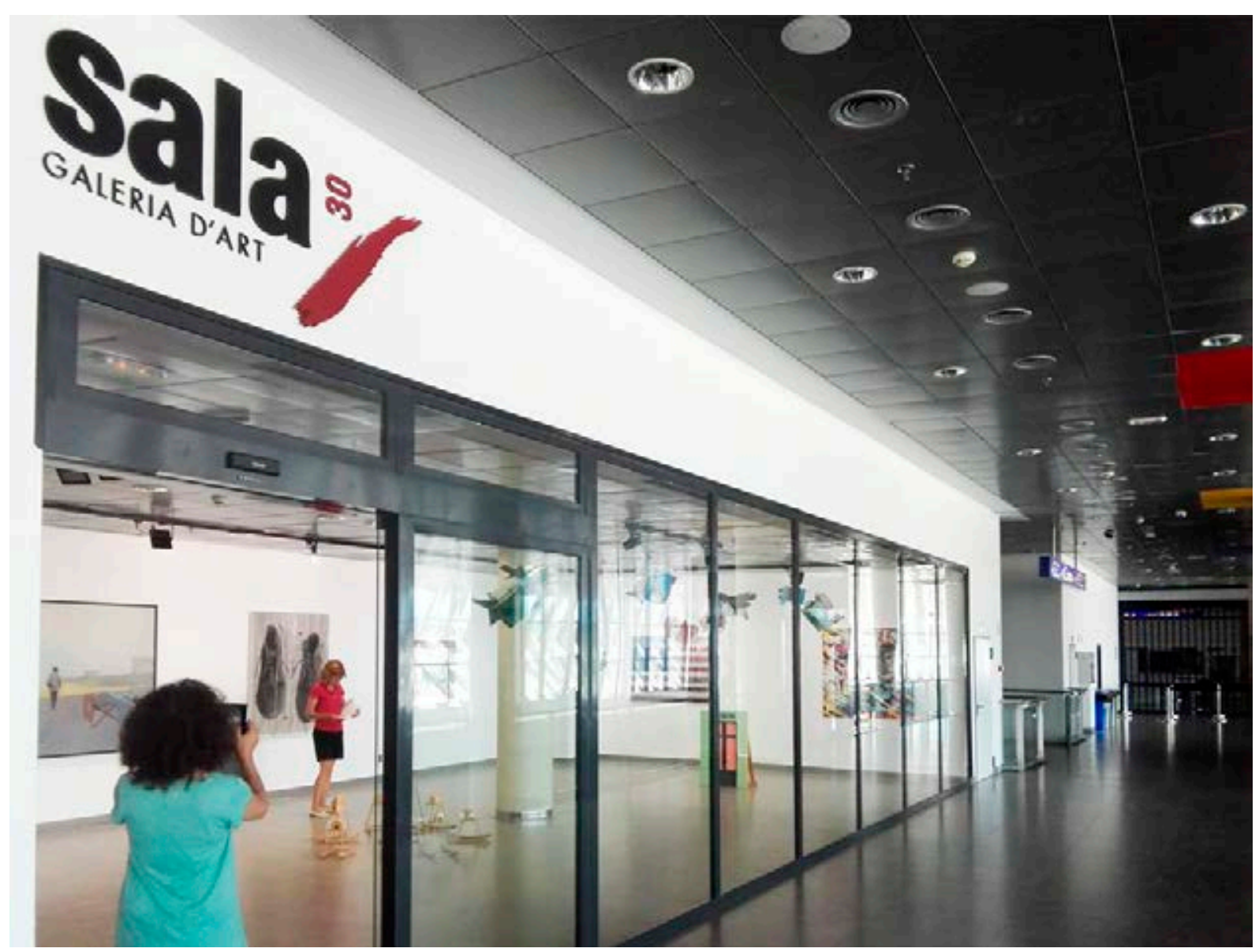

Sala 30. Exposición CV-13 En ruta, 2019. Aeropuerto de Castellón. Fotografía: Joan Feliu

ladores con alas de metal, 2019) ${ }^{14}$ y Santiago Gómez Carreras (Ciudad mecedora, 2015).

Los y las artistas nos incitaron a departir con sus atractivas propuestas fruto del desplazamiento y la interiorización de sus vivencias. Como muestra mencionamos Viajes, realizada ex professo para la exposición, en la que la pompa de jabón de primer término nos hablaba sobre la fugacidad de la experiencia viajera; UNITED, como reflexión sobre el deseo de viajar y el sueño americano; Preparados para

14 Victoria Cano en colaboración con el técnico informático Javier Campos realizó dos vídeos cuyos enlaces QR se encontraban a disposición de los pasajeros y turistas que fueran a ver la exposición en la Sala 30. Dichos enlaces también se incluyeron en el catálogo de la exposición.

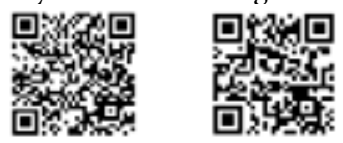

el impacto, fruto de sentirse el artista como un pasajero de un vuelo low-cost a quien se le roba lo que realmente importa, el tiempo; Ciudad mecedora, la búsqueda de espacios donde cobijarse al huir del hambre, de las guerras, o de la violencia conducen al artista a imaginar ciudades que abran sus puertas y acojan con valentía a los que por obligación han de desplazarse. Así pues, gracias a sus componentes materiales y afectivos, el arte nos condujo a un extrañamiento que puso en cuestión nuestras certezas y rutinas, en un recorrido sin pausa hacia otros espacios y otras culturas.

$\mathrm{Al}$ entrar o al abandonar el aeropuerto, nos fijamos en el conjunto escultórico emplazado en el corredor central de entrada al edificio Al vuelo (2012) de la artista valenciana Fanny Galera. Se trata de una escultura en la que pre- 


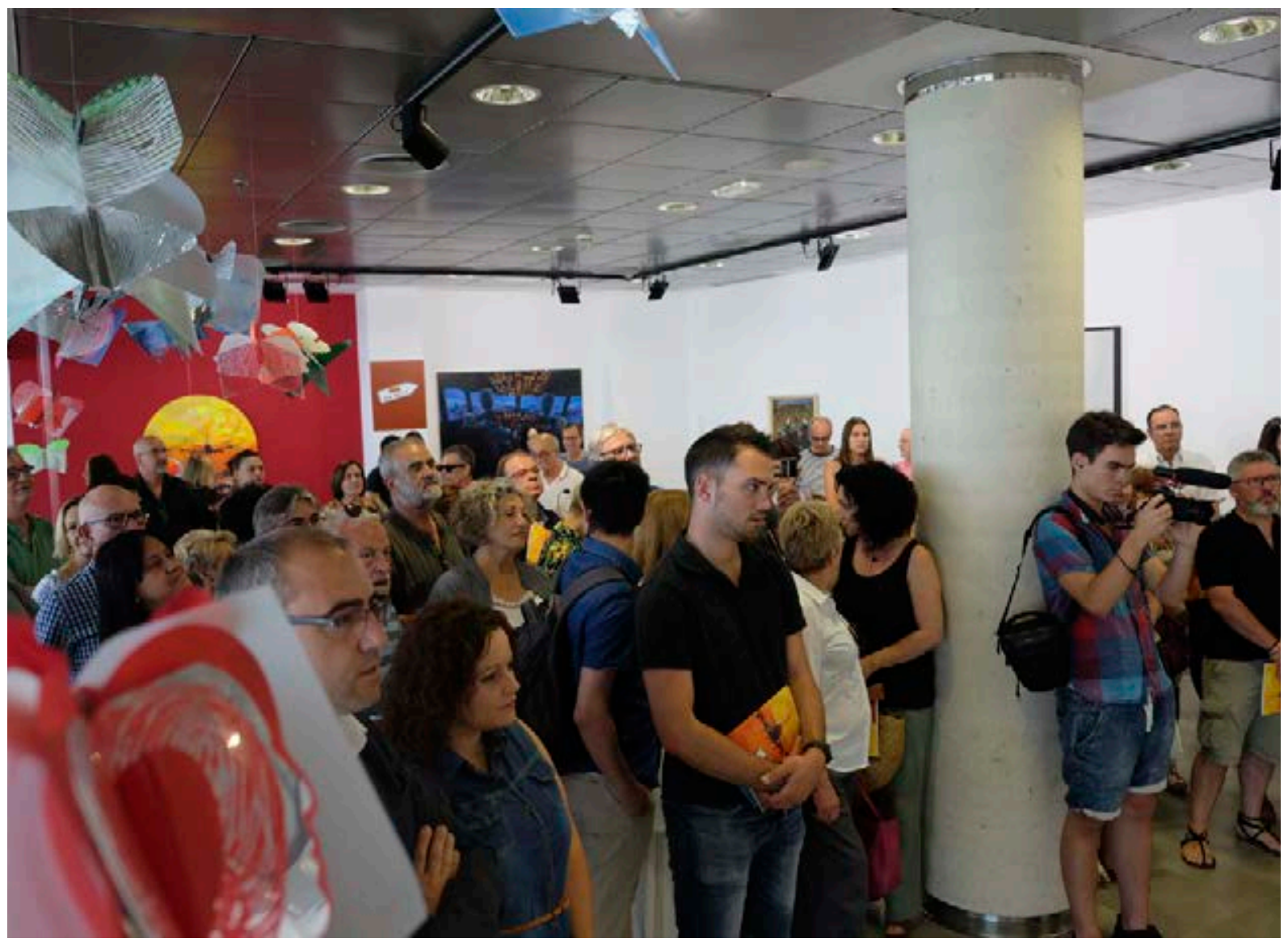

Sala 30. Exposición CV-13 En ruta, 2019. Aeropuerto de Castellón. Fotografía: Martíllopis

valece la puesta en escena. Tres personajes andróginos, sin ropa, pelo o atributos, a la caza de objetos que parecen labios, que parecen besos. Su significado nos es revelado en parte por unas líneas del breve texto que se escribió con motivo de la exposición Respiro tus silencios en la Galería ARANAPOVEDA: «Los labios presentes en muchas de las piezas ceden su condición de objeto, a la función del beso y así, a modo de metáfora, plantea su elección por una expresividad positiva ante la vida y una energía regeneradora que sirva de contrapunto a lo negativo, y las palabras ceden su lugar al gesto» ${ }^{15}$.

15 Nota de prensa (2011) <https://www.plataformadeartecontemporaneo.com/pac/\%E2\%80\%9Crespiro-tus-silencios\%E2\%80\%9D-fanny-galera-en-aranapoveda/> [consulta: 20/09/2019]
La artista consigue crear una atmósfera única con la elección y tratamiento de materiales como la resina acrílica, la fibra de vidrio, el hierro y la malla metálica, al tiempo que manifiesta las inquietudes del individuo, esa imperiosa necesidad de no dejar escapar las oportunidades que se nos brindan en nuestro particular viaje personal.

¿Quién podría imaginarse que los espacios aeroportuarios podrían proporcionar sorprendentes, e incluso gratificantes, experiencias artísticas? Sirvan estas líneas como selecto encaje para un inacabado ágape de gustos y sabores. 
Alberola Crespo, Nieves y Zuriaga Senent, Vicent F. (2019) Catálogo de la exposición de la Sala 30 del Aeropuerto de Castellón CV-13 En ruta, Castellón: Generalitat Valenciana.

Barrionuevo Pérez, Raquel (2012) «Fanny Galera: el transitar de la existencia hecho escultura», Revista Octubre Art i Disseny 6, Castellón: Servei de Publicacions Universitat Jaume I de Castelló.

BAskas, Harriet (2019) «Welcome Back: Cool(est) Art at Seattle-Tacoma International Airport», <https:// stuckattheairport.com/2019/05/17/welcomeback-coolest-art-at-seattle-tacoma-internationalairport/> [consulta: 12/09/2019]

Bontemps, Valentin (2019) «Art on the go at Charles de Gaulle airport»<https://www.expatica.com/fr/outand-about/excursions/art-on-the-go-at-charles-degaulle-airport-107863/> [consulta: 15/09/2019]

Drawhorn, Omie (2018) «A Tree to Take Root in the North Satellite», <https://www.portseattle. org/blog/tree-take-root-north-satellite $\quad$ [consulta: $12 / 09 / 2019]$

Feliu, Joan (2018) Catálogo de la exposición de la Sala 30 del Aeropuerto de Castellón Nunca los lejos estuvieron tan cerca, Castellón: Generalitat Valenciana.

Griffin, Amy (2016) «Founder of Arts Program at Albany Airport Departing», <https://www. timesunion.com/tuplus-features/article/Founderof-arts-program-at-Albany-airport-8355034.php> [consulta: 15/09/2019]

Grondahl, Paul (2012) «At the airport, an uplifting experience», <https://www.timesunion.com/ local/article/At-the-airport-an-upliftingexperience-3653718.php\#item-85307-tbla-10> [consulta: 15/09/2019]

Kushner, Jason (2018) «Mini Projection Mapping and the Flight of Cupid», <https://www. digitalsignageconnection.com/mini-projectionmapping-and-the-flight-of-cupid> [consulta: 14/09/2019]

MCCARTHY, Annemarie (2017) «Now you can see famous Dutch masterpieces without ever leaving Amsterdam airport» <https:/www.lonelyplanet. com/articles/rijksmuseum-amsterdam-airport-art $>$ [consulta: 14/09/2019]
Mir, Patricia (2017) Catálogo de la exposición de la Sala 30 del Aeropuerto de Castellón Cal-ligrafies convergents, Castellón: Generalitat Valenciana.

NicE, Hannah (2018) «10 Airports with Killer Art Collections», <https://artzealous.com/10-airportswith-killer-art-collections/> [consulta: 10/09/2019]

Niккнан, Roya (2009) «Heathrow Terminal 5 to become art gallery», <https://www.telegraph. co.uk/culture/art/art-news/5661154/HeathrowTerminal-5-to-become-art-gallery.html> [consulta: 15/09/2019]

Robertson, Ania (2017) «City, ATL leaders dedicate art installation 'Flight Paths'», <https://www.atl. com/city-atl-leaders-dedicate-art-installationflight-paths/> [consulta: 10/09/2019]

SÁnchez, Marta (2017) «Yayoi Kusama. Biografía, obra y exposiciones», <http://www.alejandradeargos. com/index.php/es/completas/32-artistas/41530yayoi-kusama-biografia-obra-y-exposiciones $>$ [consulta: 10/09/2019]

SwifT, Cathy (2019) «Five Favourites from the Sea-Tac Public Art Collection», <https://www.portseattle. org/blog/five-favorites-sea-tac-public-artcollection $>$ [consulta: 12/09/2019]

VV.AA. «Airport Art Program. Hartsfield-Jackson Atlanta Airport». Página oficial del Aeropuerto Internacional Hartsfield-Jackson Atlanta <https:// www.atl.com/about-atl/airport-art-program/>

VV.AA. "Art and Culture Program. Albany International Airport». Página oficial del Aeropuerto Internacional de Albany <http://albanyairport.com/ art>

VV.AA. «Art at Sea-Tac Airport». Página oficial del Aeropuerto Internacional de Seattle-Tacoma $<$ https://www.portseattle.org/page/art-sea-tacairport>

VV.AA. «Denver International Airport's Art and Culture Program». Página oficial del Aeropuerto Internacional de Denver, Colorado <https://www. flydenver.com/about/art_culture/program> 


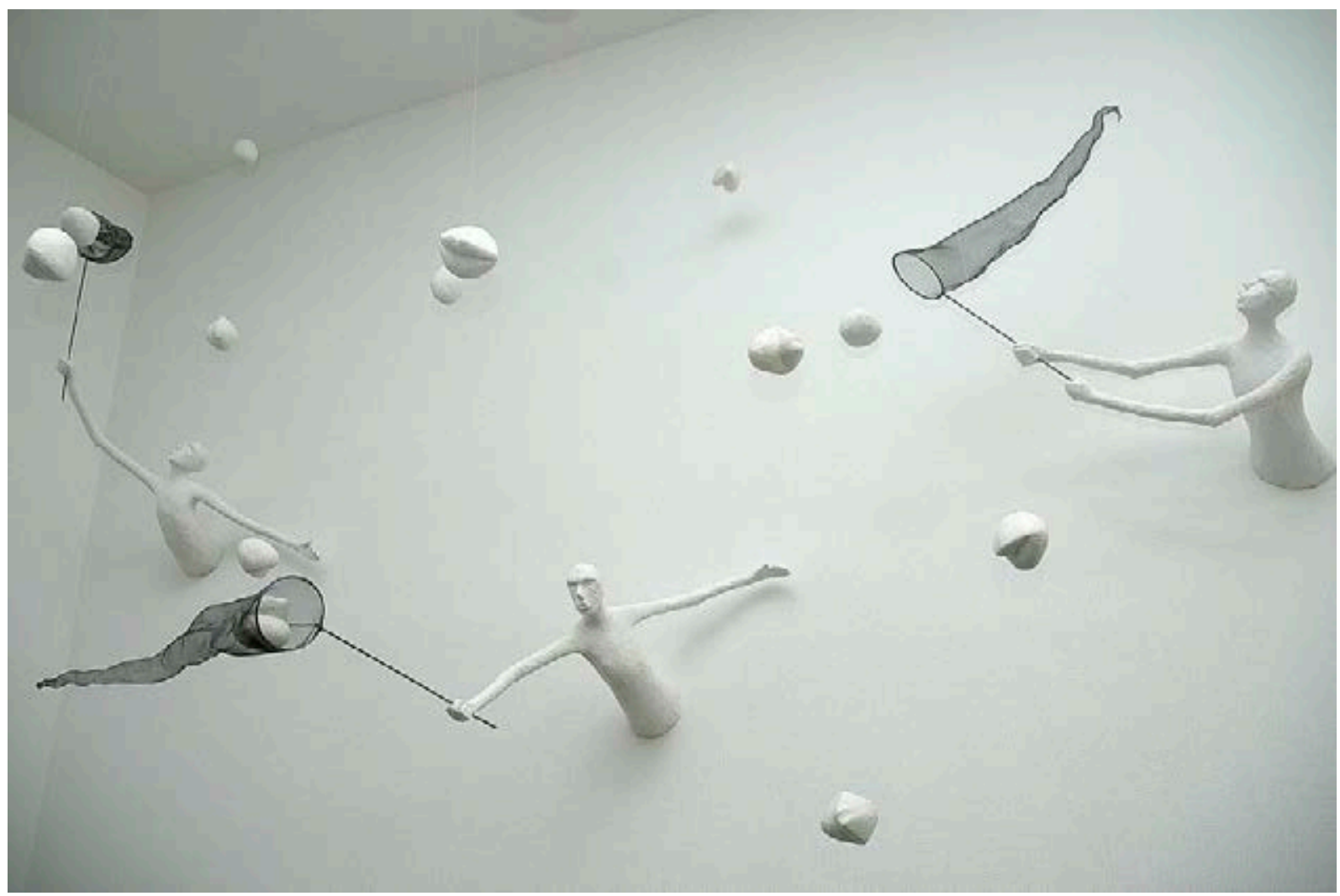

Fanny Galera, Al vuelo, 2012. Aeropuerto de Castellón. Fotografía: cortesía de la artista

VV.AA. «L'Espace Musées. Aéroport Paris-CDG». Página oficial del Aeropuerto de Paris-CDG $<$ http:// espacemusees.com/>

VV.AA. «Rijksmuseum Schiphol». Página oficial del Aeropuerto Schiphol https://www.rijksmuseum.nl/ en/schiphol

VV.AA. «San Francisco International Airport's Public Art Program». Página oficial del Aeropuerto Internacional de San Francisco <https://www. sfomuseum.org/public-art>

VV.AA. «Sala 30. Galeria d'Art». Página oficial del Aeropuerto de Castellón-Costa Azahar <https:// www.aerocas.com/es/sala-30>
VV.AA. «T5 Art Gallery London Heathrow Airport». Página oficial del Aeropuerto de Heathrow <https:// www.highperformanceart.org.uk/>

Woмack, Katie (2016) «Another Reason to Love Gary Sweeney, Creator of "America, Why I Love Her"», $<$ https://www.westword.com/arts/another-reasonto-love-gary-sweeney-creator-of-america-why-ilove-her-7607464> [consulta: 10/09/2019]

Este artículo se enmarca dentro del proyecto de investigación UJI-B2018-73 «L'espacialitat com a construcció cognitivoemocional en l'àmbit literari». 